\title{
Sustainable Aquaculture
}

\section{Kuo-Kau Lee*}

Department of Aquaculture, National Taiwan Ocean University, Taiwan

*Corresponding Author: Kuo-Kau Lee, Department of Aquaculture, National Taiwan Ocean University, Taiwan. Tel: (888) 224622192; E-mail: b0092@mail.ntou.edu.tw

\section{Introduction}

Aquaculture has been practiced for many centuries referring to the breeding, raising, and harvesting of aquatic plants and animals in all types of water environments (fresh water, brackish water and seawater) for food, sport, bait, ornamental and conservation/stock restoration purposes. Historically, common carp were cultured for human consumption in freshwater ponds as early as 1100 B.C., while oyster farming has been recorded as early as the Han Dynasty about two thousand years ago in China ${ }^{[1]}$. Some other early examples of aquaculture related activity include the Japanese culturing oysters for pearls, together with those for food purpose such as the stocking fish in ponds by ancient Egyptians, raising eels by the Greeks and Romans and farming oysters by the Europeans. However, since then, aquaculture remained substantially a low-level, small-scale, subsistence farming activity until major experimental husbandry practices for salmonids and a considerable group of tropical fish and shellfish were conducted, developed and adopted for the industry in the mid- $20^{\text {th }}$ century ${ }^{[2]}$.

In general, aquaculture is the farming/rearing of aquatic organisms including mammals (whales, dolphins, seals etc.), reptiles (crocodiles, alligators, turtles, soft-shell turtle etc.), amphibian (frogs etc.), cartilaginous fish (sharks etc.), finfish, invertebrates (crustaceans, mollusks, bivalves, sea cucumbers etc.) and aquatic plants (algae, seaweeds etc.). Furthermore, the aquaculture aspect is highly diverse in terms of culture species, systems, environment, scale, intensity, management and marketing. Once the aspect of marine biology research is considered together, the background of the scientists and researchers has varied wider, including biology, anatomy, nutrition, physiology, ichthyology, microbiology, pathology, fish diseases, biotechnology, pharmacology, ecology, marine pollution and engineering, economy, and others.

Currently, aquaculture is booming and has been reported as the fastest growing food producing sector worldwide, with an average annual growth rate of $8.9 \%$ since 1970 , compared to only $1.2 \%$ for capture fisheries and $2.8 \%$ for terrestrial farmed animal production over the same period ${ }^{[2]}$. As described by The World Bank Group ${ }^{[3]}$, aquaculture has been projected to be the major source of seafood by 2030 as demand may grow from the global middle class and production from wildcaught fisheries may nearly approach their maximal. Aquaculture production may help provide livelihoods and feed a global population that will reach nine billion by 2050 once the industry is practiced responsibly and sustainably ${ }^{[3]}$. A truly sustainable aquaculture system regarding to environmental, social \& community and economic sustainability remains as a big issue globally.

Some essential practices are therefore suggested to be considered in fulfillment of responsible and sustainable aquaculture development $t^{[3,4,5]}$.

\section{Received date: August 19, 2015 Accepted date: August 20, 2015 Published date: August 21, 2015}

Citation: Lee, K. K. Sustainable Aquaculture. (2015) J Marine Biol Aquacult 1(1): 12- 13 .

Environment Practices: Avoidance of destruction on coastal mangrove and wetland; climate change mitigation and adaptation; effective effluent management and water quality control; sediment control and sludge management; soil and water conservation on farm sites; efficient fishmeal and fish oil use(favoring plant-based feeds); responsible sourcing of brood stocks and juvenile fish (favoring native species and preventing introduction of exotic organisms); control of escapes and minimizing impact on biodiversity and wildlife.

Community Practices: Establishing well-defined rights, aquaculture zones (land, lake or sea etc.) and responsibilities for aqua-culturists; regulatory compliance and effective enforcement; community involvement; worker safety, fair labor practices and equitable compensation.

Sustainable Business and Farm Management Practices: Effective biosecurity and health management systems; minimizing antibiotic use and drug abuse; microbial sanitation; maintaining global standards for hygiene; efficient and humane rearing, harvest and transport (animal welfare) ; accountable record-keeping and traceability; profitability; promoting 
sustainably grown aquaculture products to the market and individual consumers.

Journal of Marine Biology and Aquaculture (JMBA) is an internationally open access journal and serves a variety of purposes for the exploration, improvement and management of all freshwater and marine food resources. The journal is dedicated to publish peer-reviewed articles related to original and novel fundamental research in the field of Aquaculture and Marine Biology. In addition, the main aim of the journal is to provide an interdisciplinary forum for research scholars, scientists and other professionals to find most original research in the field Aquaculture research. As sustainable aquaculture is a dynamic concept and needs continued advances in technology and management practices to be broadly applied in producing a variety of species for both restoration and commercial purposes. Hopefully, through continual publication of quality articles, our journal may contribute to the development of sustainable/responsible aquaculture and thence makes JMBA sustainable as well.

\section{References}

1. Hishamunda, N., Subasinghe, P.R. Aquaculture development in China: the role of public sector policies. (2003) FAO Fisheries Technical FAO 427: 64.

2. Bondad-Reantaso, M.G., Subasinghe, R.P., Arthur, J.R., et al. Disease and health management in Asian aquaculture. (2005) Vet Parasitol 132(3-4): 249-272.

3. Sustainable Aquaculture. (2014) The World Bank Group. 4. Diana, J.S., Egna, H.S., Chopin, T., et al. Responsible aquaculture in 2050: Valuing local conditions and human innovations will be key to success. (2013) BioScience 63(4): 255-262. 5. Hall, S.J., Delaporte, A., Phillips, M.J., et al. Blue Frontiers: Managing the Environmental Costs of Aquaculture. (2011) The World Fish Center Penang Malaysia. 